\title{
Exposition of Medical History: A Metaphorical Image or a Collection of Objects?
}

\author{
Maria Pavlovna Kuzybaeva \\ FSBE SRI of the History of Medicine, \\ Russian Academy of Medical Sciences \\ Lane B, Nikolovorobinskiy 7, building 15, \\ Moscow 109028, Russia \\ E-mail: kuzibaeva@inbox.ru
}

A significant part of the Russian museum sphere is comprised of the less known museums of medical research institutes and clinics which operate on a voluntary basis. The museum at the Russian Research Centre of Surgery (RSCS) by the name of Academician Boris Vasilevich Petrovsky has been around for more than fifteen years. The museum's exposition is regarded as an example of a highly original solution to the problem which could be stated as follows: which should be considered more important in the setup of an exhibition-a metaphorical image or a collection of authentic objects?

Today, the exposition is seen as an essential part of a museum's communication, as it is not reproduced by other public institutions. An exposition's design, development and operation, especially on such a complex subject as medicine in general and contemporary high-level medical technologies, require profound development of methodology based on modern principles of museology. It is not surprising then that when analyzing the work of museums of medicine in Russia and the Soviet Union we will find very few examples of a successful solution for temporary and permanent exhibitions devoted to a specific subject.

A pleasant exception to this situation is the permanent exposition of the Museum of the B. V. Petrovsky Russian Scientific Centre of Surgery, which was created with the active participation and support of Boris Petrovsky, the founding father of Russian surgery, who paid close attention to the preservation and presentation of historical and medical heritage at the centre. 
The background and the main objectives

The idea of creating a museum at the RSCS began to formulate in the early 1980s. A great deal of effort went into organizing the new division by E. N. Vantsyan, a corresponding member of the Russian Academy of Medical Sciences, and Professor G. E. Chesnokova, who also became the first director of the museum.

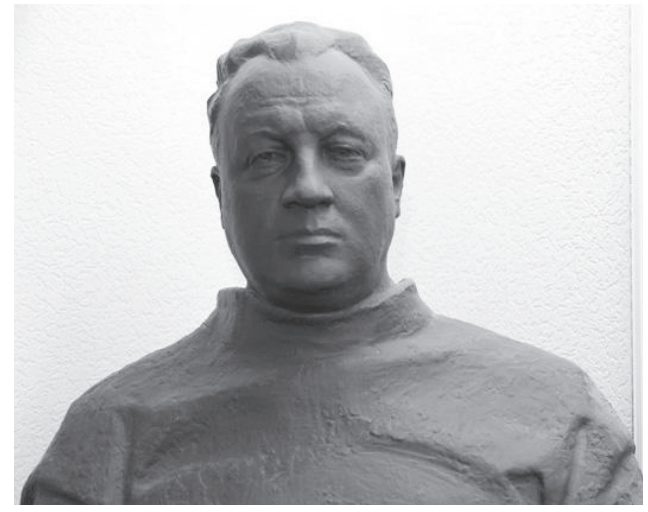

The bust of Academician Boris Vasilevich Petrovsky. (2008)

Chesnokova took active part in the formation of the museum's collections. The museum of medicine has been developing as a repository for the scientific and cultural heritage of the past, thus contributing to the continuity of traditions by new generations of doctors. This became one of the motivations for the acquisition and exhibition work. Boris Petrovsky pointed out:

While turning the pages of the chronicles, one can see how the historical traditions and achievements of Russian science and culture, their continuing validity and value of the formation and education of doctors have merged. (Kratkaia istoriia RNCH, n.d.)

This statement formed the basis for the scientific concept of the future exposition. Its main goal was stated as follows-disseminating information about the history of medicine and achievements in modern times through artifacts which are systematized according to the profile of the surgical activity at the institution. National health-care specialists with higher and secondary medical education have been improving their knowledge since the establishment of the centre to train scientific and medical personnel of higher qualification in the RSCS. The centre incorporated five chairs of the first I. M. Sechenov Moscow State Medical University and two chairs of the Russian Medical Academy for postgraduate education (RNCH, 1997-2010). The Museum fulfils its educational function through the exhibition and highly professional guided tours.

The question of how to reflect in the museum's exposition "the original research, development and introduction of up-to-date local and foreign medical technology in the fields of cardiac surgery, vascular surgery, intervention and endoscopic 
surgery, surgery of the liver, biliary tract and pancreas, lung and mediastinal surgery, coloproctology, plastic and maxillofacial surgery, reconstructive surgery, organ transplantation, including family and pediatric spine surgery, neurosurgery, radiology, clinical dashboard metrics and transfusiology, immunology, anesthesiology and reanimatology" (RNCH, 1997-2010), as they have been performed at the RSCS, was presented to professors of medicine, designers, artists, the museum's staff, and engineers.

Academician Boris Petrovsky, the centre's director, personally supervised the work of the team of medical scientists and museum's staff members in the 1980s. He drew attention to the fact that in addition to the conservation of heritage and popularization of modern achievements in medicine in the diagnosis and treatment of many diseases, the museum has an important representational function, because, among other things, it presents an opportunity to promote the centre as the largest multi-functional surgical research and clinical institution.

The RSCS Centre organizes scientific congresses, conferences, symposia and seminars to train physicians and health-care providers in Russia, exchange experiences and discuss topical issues. Participants in these events make up a significant number of the museum's visitors. The mission of the museum lies not only in the preservation and popularization of medical heritage, but also in advancing museology, disseminating experiences among colleagues, providing scientific advice to regional museum structures, composed of institutes, clinics, hospitals, etc. The latter activity has not been sufficiently tackled with in research papers and publications on museology thus far. The museum has had its permanent exposition, with some modifications and additions, for over fifteen years. It is a living and scientifically highly unique embodiment of tasks and ideas formulated by Boris Petrovsky.

\section{Exposition as a metaphor-or a synthesis of techniques?}

Advances in museum technology enabled the museum to update and advertise its collections as late as at the end of the $20^{\text {th }}$ century. The artistic presentation of the exposition in the scientific museum is the key to the success of the work done. The selection of exhibits, as well as the preparation of general and thematic sections, was carried out by the scientific staff. They held creative brainstorming sessions with designers and artists, whose decisions violated the integrity of the carefully 
designed and built exhibition constructions. The disputes and discussions resulted in the only possible artistic solution for the future exhibition-a metaphorical figurative approach was applied in the decoration of halls and in the presentation of a large number of exhibits in the RSCS Museum.

Specially designed constructions played an important role in the setup of the exposition. In smaller rooms, the limited space is divided by a figured partition and also a dark green display used for exhibiting in-plane and

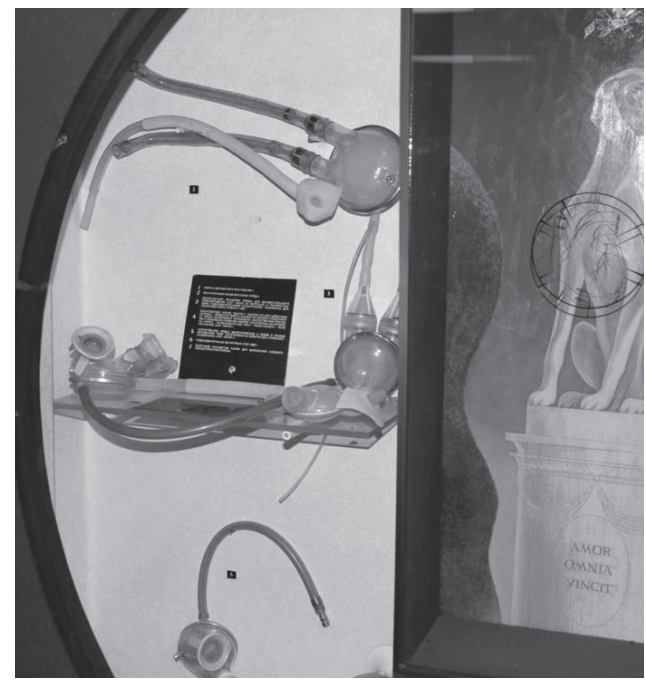

The artificial heart. Fragment of exposition. (2011) other items. Installed in several halls, this partition has become the unifying element in numerous exhibition complexes, reflecting the basic structures of the centre. Beautiful pictures and musealia grouped around them became a symbolic image, a spiritual metaphor for surgical operation. For instance, the display of an artificial heart, created in the Soviet Union, constitutes a significant part of the heart transplant section.

Here the spectator can see a collection of original Russian surgical stapling instruments, artificial heart valves, pacemakers. Tools designed by the centre's staff occupy a special place in the display cases: here's a unique needle clip by Boris Petrovsky used for resection of heart aneurysm, an ultrasound tool kit for operating in the pleural cavity, a set of silicone prostheses of trachea and bronchi, radiopaque esophageal bougies, nitinol endoprostheses by I. Kh. Rabkin, which were first successfully used in 1984 at iliac artery dilatation in the case of severe limb ischemia. The RSCS museum is also the only place where a visitor can get closely acquainted with the microscope for microsurgical operations. Lighting draws attention to the main exhibits and gives the visitors a chance to closely observe radiographs. Numerous photographs, surgical plans, scientists' portraits, copyright certificates, personal items belonging to the RSCS researchers complement the exposition and engage the spectator in the wonderful world of high-tech medicine, demonstrating the intense pace of their everyday work. 


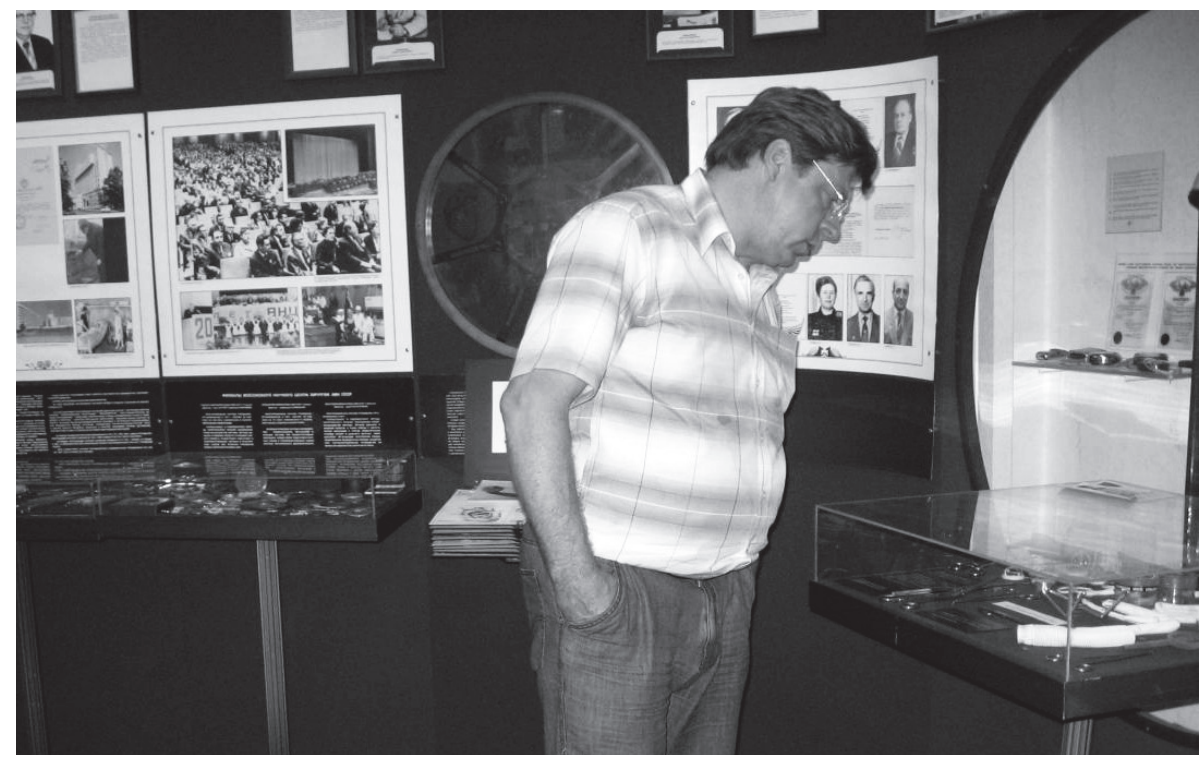

Surgical instrument collections are of great interest to modern surgeons. (2009)

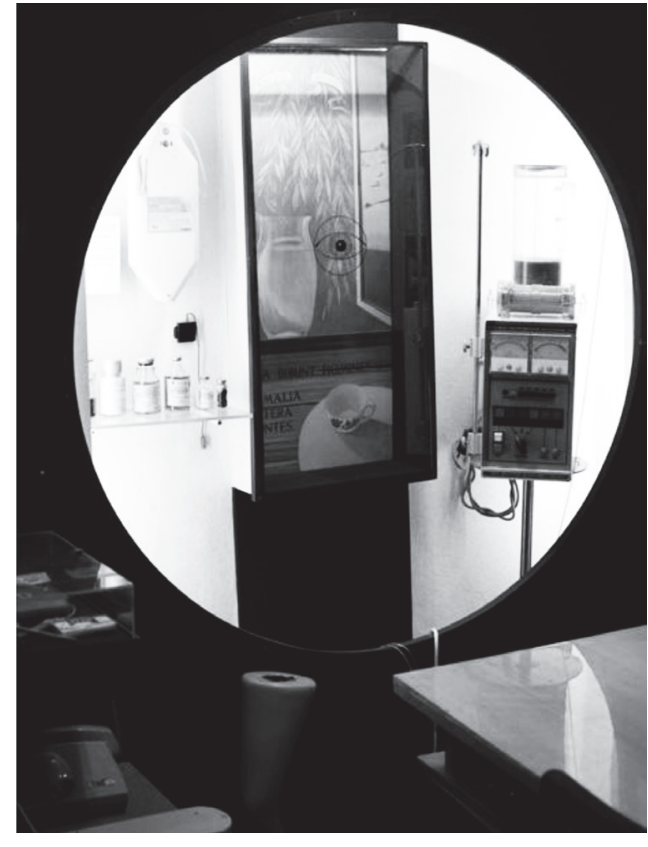

Kidney transplantation. Fragment of exposition. (2008)
The exposition of the RSCS scientific museum leaves an unexpected impression that the generalized image of surgery and related fields of medicine complements the unique collection of museum objects. The metaphorical approach applied in the organization of this exhibition has not become an aesthetic end in itself, but has given a novel view on innovation in medical practices, attested by material musealia, and presented it to the audience. The collection of the multitude of objects is fairly justified and appropriate. One should not forget that the RSCS museum is oriented to a numerous specialized audience 


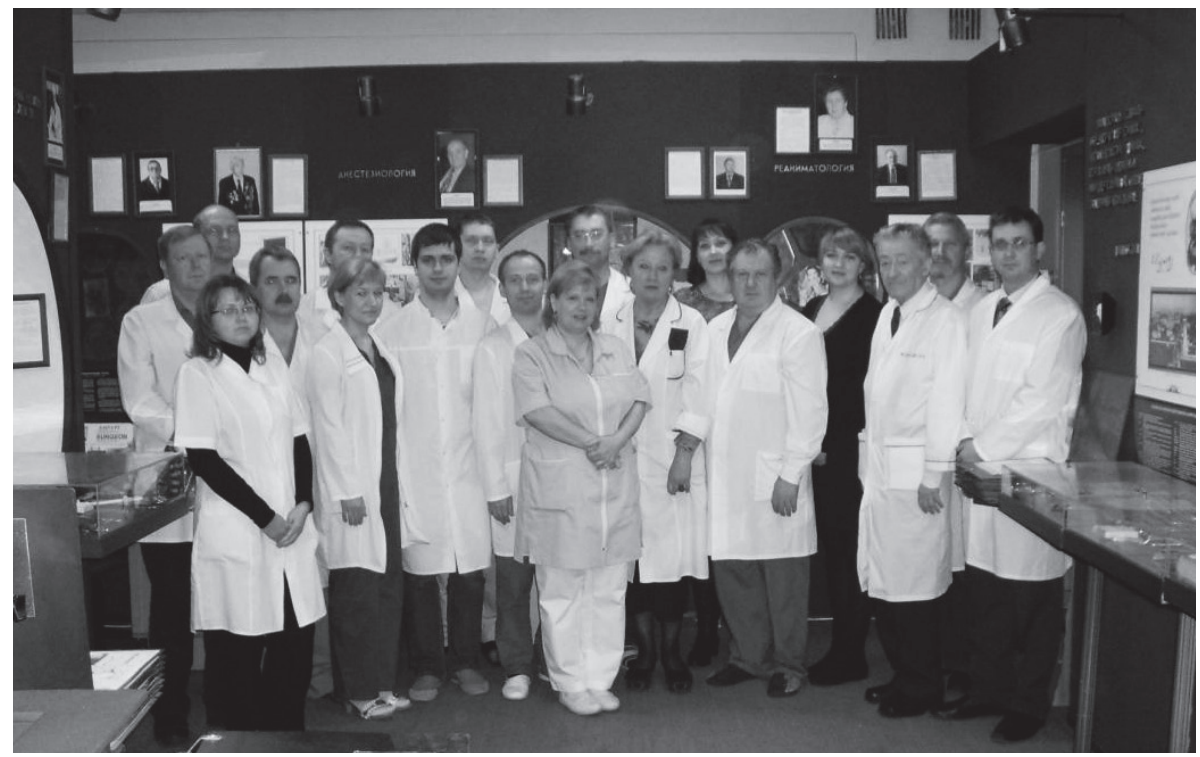

Interns and doctors in the museum with Y. U. Rabinovich, Doctor of Medicine (second from right). (2008)

of individuals who wish to improve their surgical knowledge and skills at postgraduate level, and also senior students and nurses. They are not only resident doctors, interns, postgraduate students, but also practitioners from all across the Russian Federation.

The RSCS is not only a practical guide to innovation in regional and global health care, but also widely promotes it, helps doctors understand and apply innovations, organizes master classes, and special education training cycles, while applying this enormous educational potential of its unique museum.

\section{How do the objects "speak" today? In lieu of a conclusion}

Today's challenges actualize the museum community's mission to make a medical exposition highly interactive, making the displayed objects engage with the audience, and develop a special language that is understood by both professionals and the lay people. The metaphorical approach to understanding and implementing these objectives, which became a milestone in the evolution of museum management in the medical field in the $20^{\text {th }}$ century, has not outlived 
its usefulness so far. We believe that by using advances in science and technology and media, based on the proven methodology of the exposition in the museums of leading research institutes of the Russian Federation, it is possible to create a museum exposition specializing in medicine that would respond to the demands of the early $21^{\text {st }}$ century. The possibilities of modern medicine, particularly hightechnological telecommunications and interventional use of such sophisticated surgical techniques as "reverse remodeling" of the human heart are the main trends and themes of the museum's new exhibition. We will soon be able to see how these challenges will be addressed. One thing is clear-the main focus will be on the museum objects which have been most recently the conventional tools in clinical practices. Once displayed in the museum, they have acquired a different status and value, found their specific "voice" and started "talking" with the visitor.

The language of the "dialogue" between the museum exhibits and the general public in the museum is expressive and simple at the same time. The multilayered meanings in such discussions are mainly conveyed by the musealia of the tools section, which have been interpreted by the museum staff according to the target and professional orientation of visitors. Expansion, updating and improvement of the museum of the Petrovsky Russian Research Centre of Surgery, especially that of its exposition, will be the main objective in the coming years.

\section{References}

Kratkaia istoriia RNCH (n.d.) Federal'noe gosudarstvennoe biudzhetnoe uchrezhdenie "Rossiiskii nauchnyi tsentr khirurgii imeni akademika B.V. Petrovskogo" Rossiiskoi akademii meditsinskikh nauk: Istoricheskaia spravka. Kratkaia istoriia RNCH. Official home page of the B. V. Petrovsky Russian Scientific Center of Surgery, Russian Academy of Medical Sciences. Retrieved from http://www.med.ru/patient/history [accessed 28 Jun 2012]

RNCH (1997-2010), Rossiiskii nauchnyi tsentr khirurgii. Official home page of the B. V. Petrovsky Russian Scientific Center of Surgery, Russian Academy of Medical Sciences. Retrieved from http://www.med.ru/specialist/index.php [accessed 28 Jun 2012] 